\title{
PREDICTING THE IMPACT OF THE EU COMMON AGRICULTURAL POLICY REFORM IN ENGLAND: MICRO AND MACROECONOMIC ASPECTS
}

\author{
Francisco J. Areal ${ }^{1}$, Michele G. Ceddia ${ }^{2}$, Pasquale Pazienza ${ }^{3}$
}

${ }^{1}$ Central Science Laboratory, Sand Hutton, York,YO41 1LZ, United Kingdom,e-mail: f.areal@csl.gov.uk ${ }^{2}$ University of York, Environment Dept., Heslington, York, YO10 5DD, United Kingdom, e-mail: mgc103@york.ac.uk ${ }^{3}$ Università di Foggia, DSEMS, L. go Papa Giovanni Paolo II n. 1, 71100, Foggia, Italy, e-mail: p.pazienza@unifg.it

Received 1 March 2007; accepted 25 March 2007

\begin{abstract}
In this article we investigate the effects of the European CAP reform on a selection of arable crops in England, both at a regional and national level. The results show that the CAP reform will push farmers to adjust to the new market conditions, which will cause a further restructuring of the English agricultural business sector. Our results show that, under the new market conditions, economically-small farms will increase their output by allocating more land to cereals, whereas economically-large farms will need to decrease land allocated to cereals to reduce production costs and achieve better returns.
\end{abstract}

Keywords: Agricultural business management, economic impacts evaluation, CAP reform.

\section{Introduction}

The 2003 reform of the European Common Agricultural Policy $(\mathrm{CAP})^{1}$ has stimulated a wide debate among farmers, policy makers and the general public, as it is likely to change the business behaviour in the sector. Broadly speaking, the reform is centred around the introduction of a "single payment" mechanism from 2005 onwards, and the full decoupling of (public) support for production in the reformed sectors (i.e. arable, sheep, beef, olive oil and cotton) $)^{2}$. As a result of this, the reform may have consequences for agriculture in Europe as well as in England. For this reason, to perform an ex-ante evaluation seems appropriate to understand the future trends in the considered business sector.
A number of studies have already been carried out to evaluate the effects of the European policies on the agricultural sector of various countries in general or with respect to a particular industry (Benjamine et al., 1999; Bouamra Mechemache and Réquillart, 2000; Moss et al., 2002; Burrel, 2004; Colman et al., 2004; Grant, 2003; Harris, 2005; Swinbank and Tranter, 2004). The originality of our study is based on the use of a dataset provided by the British Department for Environment, Food and Rural Affairs (Defra), which allows us to account for regional differences in England. Defra estimated the subsidy receipts by farm type and by region between 2005 and 2012 (Defra, 2004). We used this information, along with our panel data model estimates, to assess over the same period, 2005-2012, the impact

\footnotetext{
1 This study refers to the implementation of the CAP as agreed in Luxemburg on 26 June 2003 and 24 April 2004 (as a second wave reform). This latest reform covers the sectors of tobacco, hops, olive oil and cotton, for which the European Commission made a reform proposal on 18 November 2003.

2 The eligibility of the "decoupled" single payment scheme and the rural development measures are linked to environmental, food safety, plant health and animal welfare aspects, as well as the requirement to keep all farmland in good agricultural and environmental condition (i.e. the so-called cross-compliance requirement).
} 
of the CAP reform on land allocated to a set of arable crops: wheat, barley and oilseed rape ${ }^{3}$.

Before giving the subject any consideration, it is important to observe that once the CAP reform enters into force farmers can behave in two different ways: either they comply with the new regulations or they do not. If a farmer does not comply then he would not be entitled to the single payment (SP). On the other hand, if he complies with the regulations the payment he will receive will depend (among other things) on the farm type and size (Defra, 2004) ${ }^{4}$. Of course, farmers' behaviour after the implementation of the CAP reform is unknown. Nevertheless, our study gives information about how changes in the payments and prices can affect farmers' management decisions, particularly in terms of land allocation to individual crops. Having said this, the rest of the work is organised as follows. Drawing on mathematical programming, a simple model is developed in section two to provide the theoretical foundation of our analysis. The empirical estimation of the model and its results are discussed in section three. Furthermore, the evidence at regional level is presented in section four. Lastly, some conclusions will be drawn.

\section{The theoretical model}

Following what is commonly referred to in the specific literature, we build the foundation of our analysis in terms of a farmer's optimisation problem (e.g. Guyomard et al., 1996). We consider a production function approach, where farmers maximise their profit for given market prices while considering technical constraints, by choosing the level of output and inputs (including fixed but allocatable factors such as land). In our context, the farmer's problem can be represented in the following terms:

$\pi(p, w, s, \bar{L})=\underset{y, x, l}{\operatorname{Max}} \sum p_{i} y_{i}+\sum\left(s_{i}\right) l_{i}-\sum w_{j} x_{j}$

subject to: $y_{i}=f_{i}\left(x, l_{i}\right)$

and $\sum l_{i} \leq \bar{L}$,

with $i: 1 \ldots n$, and $j: 1 \ldots m$,

where $y_{i}=$ output of the $i$-th crop; $x_{j}=j$-th input; $l_{i}=$ land allocated to $\operatorname{crop} i ; L=$ total available land; $p_{i}=$ output price of the $i$-th crop; $w_{j}=$ price of the $j$-th input; $f=$ production function; $s_{i}=\mathrm{CAP}$ payment associated with land use $\mathrm{i}$.

After substituting constraint ( $1 \mathrm{~b}$ ) into (1a) the solution of problem $(1 \mathrm{a}-1 \mathrm{~d})$ is usually modelled in two steps (e.g. Guyomard et al., 1996). In the first step the land allocation to each crop is taken as given and the optimal variable input use is determined. This is equivalent to:

$\pi_{i}\left(p_{i}, w, s_{i}, l_{i}\right)=\operatorname{Max}_{x} p_{i} f_{i}+\left(s_{i}\right) l_{i}-\sum w_{j} x_{j}$.

At a second stage the optimal land allocation is determined by:

$\pi(p, w, s, \bar{L})=\operatorname{Max} \sum \pi_{i}\left(p_{i}, w, l_{i}\right)$ s.t. (1 c).

The Lagrangian for the problem is:

$\sum \pi_{i}\left(p_{i}, w, s_{i}, l_{i}\right)-\lambda\left(l_{i}-\bar{L}\right)$.

The first order conditions for this problem are:

$\frac{\partial \pi_{i}\left(p_{i}, w, s_{i}, l_{i}\right)}{\partial l_{i}}-\lambda=0, i: 1 \ldots n$,

$\lambda\left(\sum l_{i}-\bar{L}\right)=0, \lambda \geq 0$.

The Lagrangian multiplier $(\lambda)$ reflects the marginal benefits of releasing the constraint in $(1 \mathrm{c})$. As such, the multiplier will be positive (or zero) when the constraint is (is not) binding. This is expressed in condition (6). Expression (5) suggests that when the constraint is binding the crop specific marginal profits should all be equal to the shadow price $(\lambda)$ and therefore equal to each other. It then becomes clear that through the shadow price $(\lambda)$ the optimal land allocation to the $i$-th crop is a function not only of its own price, rent and CAP payment but also of other crop prices, rents and CAP payments, total available land and input prices. In fact by solving (5) for the land allocation $\left(l_{i}\right)$ we can write:

$l_{i}=l_{i}(p, w, s, \bar{L}), \quad i: 1 \ldots n$.

Equation (7) represents the demand function for land to be allocated to each crop and its econometric esti-

\footnotetext{
${ }^{3}$ With regard to this, it must be highlighted that our analysis is carried out for cereals farm type only. This is because, according to the Defra statistics for the years 2001-2002, they represent the second major arable land use in England, that is $11 \%$ of the total holdings (Defra, 2003).

4 It is worth noting that costs of compliance are not taken into account in this study since the details for cross-compliance are still to be set. However, according to Agra Europe (2004) it seems that cross-compliance measures will include protecting hedges and ditches by not cultivating, fertilising or spraying within two metres of the centre. Consequently it should be noted that these costs will "alter" subsidy figures.
} 
mation is a crucial objective of the present work. This requires the identification of specific functional forms that describe such a relationship. Before that, however, it is important to make some observations about the temporal dimension of expression (7). The left hand side of expression (7) indicates the land allocated to the $i$-th crop in year $\mathrm{t}$, while the right hand side will be some function of a vector of output prices, input prices, CAP payments and total land availability in the cropping year $t$. To be more precise, therefore, we should re-write expression (7) as follows:

$l_{i t}=l_{i t}\left(p_{t}, w_{t}, s_{t}, \bar{L}_{t}\right) i: 1 \ldots n$.

Unfortunately for the farmer, when the land allocation decision is taken (at the beginning of the cropping year) information about prevailing crop prices at harvest and input prices in future months might be uncertain. As such, the farmer must rely on 'expectations' about these prices. We assume that farmers base their decisions on prices prevailing in the previous year. This assumption implies a sort of adaptive expectation (Nerlove, 1958; Skokai and Antòn, 2005) and suggests that farmers do not have easy access to future markets (DG AGRI, 2001). Notice that also the information about the CAP payments is likely to be uncertain, since such payments also depend on the prevailing exchange rate between the euro and the pound. Therefore, even in this case we will refer to the level of payments available to farmers in the previous year. Information about the total available land is assumed to be known to farmers in each year. This implies that farmers know at the beginning of the cropping year how much land they want to farm in total, but have to decide how to divide it among different crops.

For our empirical purpose, we use a log-linear specification for the land allocation function, because of its advantage of making the estimated coefficients interpretable as elasticities. We also analyse two different cases:

- Case 1: where the input prices index are not included among the regressors, and expression (8) is estimated as follows:

$$
\begin{aligned}
& \ln \left(L C R_{1, t}\right)=\beta_{0}+\beta_{1} \cdot \ln \left(T A R_{t}\right)+\beta_{2} \cdot \ln \left(P C R_{1, t-1}\right)+ \\
& \beta_{3} \cdot \ln \left(P C R_{2, t-1}\right)+\beta_{4} \cdot \ln \left(S U_{t-1}\right)+\varepsilon .
\end{aligned}
$$

- Case 2: where the input prices index are included among the regressors, that is expression (8) is estimated as follows:

$$
\begin{aligned}
& \ln \left(L C R_{1, t}\right)=\beta_{0}+\beta_{1} \cdot \ln \left(T A R_{t}\right)+\beta_{2} \cdot \ln \left(P C R_{1, t-1}\right)+ \\
& \beta_{3} \cdot \ln \left(P C R_{2, t-1}\right)+\beta_{4} \cdot \ln \left(S U_{t-1}\right)+\beta_{5} \cdot \ln \left(C P_{t-1}\right)+\varepsilon,
\end{aligned}
$$

where $L C R_{i, t}$ is the land used for a specific crop $i$ at year $t, T A R_{t}$ is total agricultural area at year $t ; P C R_{i, t-1}$ is price of crop $i$ at year $t-1$; SU is CAP payments at year $t-1$ and $C P$ is an index of variable input prices relative to year $t-1$.

We estimate equations (9) and (10) for each crop (wheat, barley and oilseed rape) for the eight regions of England over the period 1992-2003.

\section{Model estimation and empirical results}

To estimate the impact of prices and CAP payments on the land allocation to different arable crops, we use a panel dataset ${ }^{5}$ containing 96 observations in this work. These are basically related to production, market prices, CAP payments received for each considered product, total agricultural area, farmers' input prices, and number of holdings in the eight regions in England (South East, South West, East Midlands, West Midlands, East Anglia, North East, Yorkshire \& Humberside, North West). The models are estimated using Ordinary Least Squares (OLS), Fixed Effect Model (FEM) and Random Effect Model (REM). The Lagrange Multiplier (LM) and the Hausman $(\mathrm{H})$ tests were used to decide between FEM/ REM and OLS and between FEM and REM estimates respectively.

We estimate the land demand function for each of the crops analysed (wheat, barley and oilseed rape) under case 1 and 2 defined above (corresponding to expression 9 and 10 respectively). The final choice between case 1 and case 2 is made on the basis of the RESET test. For both cases we then estimate the models through OLS, FEM and REM. As such, we obtain six models for each crop.

On the basis of the LM and H-test FEM are preferred to REM and OLS models in all estimations. Therefore, we focus on FEM estimates to assess the effects of changes in CAP payments and prices on the land allocated to each crop. To validate the FEM estimations, serial correlation and heteroskedasticity was tested and corrected when needed. The FEM and REM for case 1 (i.e. without input prices index) and case 2 (i.e. with input prices index) are shown in Tables 1 and 2 respectively.

\footnotetext{
${ }^{5}$ For the econometric analysis of panel data, we cannot assume that the observations are independently distributed across time (Wooldridge, 2002).
} 
Table 1. Comparison of results of land allocation models excluding production cost (dependent variable:

Crop $\log$ (no. of hectares))

\begin{tabular}{|c|c|c|c|c|c|c|}
\hline \multirow{3}{*}{ Variables } & \multicolumn{6}{|c|}{ Models } \\
\hline & \multicolumn{2}{|c|}{ Wheat } & \multicolumn{2}{|c|}{ Barley } & \multicolumn{2}{|c|}{ Oilseed Rape } \\
\hline & REM & FEM & REM & FEM & REM & FEM \\
\hline \multirow[t]{2}{*}{ Constant } & $38.60^{* *}$ & - & $-13.92 * *$ & - & -15.58 & - \\
\hline & (6.80) & - & $(0.26)$ & - & (11.52) & - \\
\hline \multirow[t]{2}{*}{ LOG Total Agricultural Land (ha) } & $-1.99 * *$ & $-3.64 * *$ & $0.299 * *$ & $4.207^{* *}$ & $1.703 *$ & 2.521 \\
\hline & $(0.49)$ & $(0.59)$ & $(0.04)$ & $(0.76)$ & $(0.12)$ & (1.58) \\
\hline \multirow{2}{*}{ LOG Subsidies t-1 (£/ha) } & $0.064 * *$ & $0.052 * *$ & $0.293 * *$ & $0.350^{* *}$ & $0.459 * *$ & $0.453 * *$ \\
\hline & $(0.03)$ & $(0.03)$ & $(0.05)$ & $(0.04)$ & $(0.12)$ & $(0.12)$ \\
\hline \multirow{2}{*}{ LOG Price t-1 (f/tonne) } & $1.184 * *$ & $1.046^{* *}$ & $0.168^{* *}$ & $0.296^{* *}$ & $0.884^{* *}$ & $0.857^{* *}$ \\
\hline & $(0.19)$ & $(0.19)$ & $(0.06)$ & $(0.05)$ & $(0.21)$ & $(0.22)$ \\
\hline \multirow[t]{2}{*}{$\begin{array}{l}\text { LOG Other crop price } \mathrm{t}-1(\mathfrak{f} / \\
\text { tonne) }\end{array}$} & $-1.039 * *$ & $-0.870^{* *}$ & -0.035 & -0.132 & $-1.010 * *$ & $-1.101 * *$ \\
\hline & $(0.19)$ & $(0.19)$ & $(0.08)$ & $(0.08)$ & $(0.22)$ & $(0.22)$ \\
\hline$A d j-R^{2}$ & 0.34 & 0.99 & 0.67 & 0.99 & 0.23 & 0.98 \\
\hline Hausman test & \multicolumn{2}{|c|}{ n.a } & \multicolumn{2}{|c|}{18.61} & \multicolumn{2}{|c|}{4.48} \\
\hline $\log -L$ & 88.71 & 132.74 & 73.84 & 116.69 & 38.32 & 52.96 \\
\hline
\end{tabular}

Standard errors in parenthesis; * significant at $5 \%$;* significant at $0.1 \%$.

- Case 1

Table 1 illustrates how farmers' decisions to allocate land to a specific crop is significantly related to the prices of the considered crop, prices of other crops and the total agricultural land area available (as expected from the theoretical analysis carried out in section 2). The table also shows that a reduction in CAP payments will have greater effects on barley, followed by oilseed rape and wheat. On the other hand, land allocation to wheat shows the largest elasticity with respect to its own price, followed by land allocation to oilseed rape and barley. The effect of changes in the price of the alternative crop is also significant ${ }^{6}$.
The negative sign on the barley price in this model entails that an increase in the price of barley will negatively affect land allocation to wheat (i.e. substitution effect). This means that farmer would grow barley rather than wheat if the relative price of barley is higher. In the barley model the alternative crop is assumed to be oilseed rape. In this case the oilseed rape price was found to not be statistically significant in explaining land allocation to barley ${ }^{7}$ (this could be due to rotational issues). When looking at the effect of total agricultural land ${ }^{8}$ on individual crops' land allocation the results are less clear.

\footnotetext{
${ }^{6}$ For the wheat model the alternative crop is assumed to be barley.

7 The variable is still kept in the model on the basis of the results of the RESET test.

${ }^{8}$ It includes crops and bare fallow, grasses and rough grazing set aside and other land on agricultural holdings.
} 
Table 2. Comparison of results of land allocation models including production cost (dependent variable:

Crop $\log$ (no. of hectares))

\begin{tabular}{|c|c|c|c|c|c|c|}
\hline \multirow{3}{*}{ Variables } & \multicolumn{6}{|c|}{ Models } \\
\hline & \multicolumn{2}{|c|}{ Wheat } & \multicolumn{2}{|c|}{ Barley } & \multicolumn{2}{|c|}{ Oilseed Rape } \\
\hline & REM & FEM $^{1}$ & REM & FEM & REM & FEM \\
\hline \multirow[t]{2}{*}{ Constant } & $54.842 * *$ & - & $-17.81 * *$ & - & $-34.352 * *$ & - \\
\hline & $(8.41)$ & - & (3.99) & - & (11.99) & - \\
\hline \multirow[t]{2}{*}{ LOG Total Agricultural Land (ha) } & $-3.027 * *$ & $-3.847 * *$ & $1.820 * *$ & $5.914 * *$ & $2.983 * * *$ & $4.803 * * *$ \\
\hline & $(0.59)$ & $(0.64)$ & $(0.27)$ & $(0.80)$ & $(0.84)$ & $(1.24)$ \\
\hline \multirow[t]{2}{*}{ LOG Subsidies t-1 (£/ha) } & $0.102 *$ & $0.103 *$ & $0.296 * *$ & $0.388 * *$ & $0.217^{*}$ & 0.192 \\
\hline & $(0.05)$ & $(0.05)$ & $(0.04)$ & $(0.04)$ & $(0.11)$ & $(0.11)$ \\
\hline \multirow[t]{2}{*}{ LOG Price t-1 (£/tonne) } & $1.143 * *$ & $1.063 * *$ & $0.298 * *$ & $0.334 * *$ & $0.535^{* *}$ & $0.465 * *$ \\
\hline & $(0.23)$ & $(0.23)$ & $(0.05)$ & $(0.05)$ & $(0.17)$ & $(0.17)$ \\
\hline \multirow[t]{2}{*}{ LOG Other crop price $t-1(£ /$ tonne $)$} & $-1.002 * *$ & $-0.911 * *$ & -0.062 & $-0.277 * *$ & $-0.625^{* *}$ & $-0.597 * *$ \\
\hline & $(0.24)$ & $(0.24)$ & $(0.08)$ & $(0.09)$ & $(0.20)$ & $(0.20)$ \\
\hline \multirow[t]{2}{*}{ LOG Cost $(£ /$ ha $)$ t -1} & -0.358 & -0.405 & 0.249 & $0.713 * *$ & -0.372 & -0.425 \\
\hline & $(0.23)$ & $(0.23)$ & $(0.16)$ & $(0.18)$ & $(0.38)$ & $(0.39)$ \\
\hline$A d j-R^{2}$ & 0.35 & 0.99 & 0.60 & 0.98 & 0.60 & 0.98 \\
\hline Hausman's test & \multicolumn{2}{|c|}{ n.a. } & \multicolumn{2}{|c|}{38.19} & \multicolumn{2}{|c|}{21.56} \\
\hline $\log -L$ & 80.06 & 117.48 & 62.35 & 112.23 & 44.81 & 62.99 \\
\hline
\end{tabular}

Standard errors in parenthesis; * significant at $5 \%$; ** significant at $0.1 \%$.

The FEM for wheat shows that the coefficient for total agricultural land is statistically significant (p-value < 0.001 ) and negative, which indicates that land allocated to wheat, will increase (decrease) if the total agricultural land decreases (increases). This may be due to the negative correlation existent between land allocated to wheat and set aside. On the other hand, land allocated to barley and oilseed rape are positively related to total agricultural land, which indicates that the negative correlation with set aside is not as strong as with wheat.

- Case 2

After checking the RESET Test the input prices index variable is significant only within the barley model. This aspect will require further investigation. With respect to the other variables the effects are not very different from Case 1 above and do not need further comment (see Table 2).
According to Defra, subsidy receipts will depend on the farm size and type. Specifically small farms are likely to be winners, compared to medium and large farms. Therefore, on the base of these predictions and the use of the model results, results by farm size are computed. Table 3 illustrates the likely impact of the CAP reform on cereal farms type according to the size of the enterprise.

The CAP reform will mainly benefit small farms in terms of land use. Conversely, large farms will be net losers under CAP reform. The area allocated to cereals in medium and large size farms is expected to decrease. As a consequence of the CAP reform, there is likely to be some shift in farm size structure by the year 2012 . This shift would be towards small and away from medium and large cereal farms, particularly in cereals and dairy. Small farms for these farm types are predicted to expand by 2012 . 
Table 3. Summary of impacts of changes in CAP subsidy support payments on change in land use for cereal farms according to farm size (defined by ESU units) in England in 2012 compared with the baseline period of 2000/02

\begin{tabular}{|c|c|c|c|c|}
\hline & \multicolumn{3}{|c|}{ Farm size } & \multirow{2}{*}{ Overall impact } \\
\hline & small & medium & large & \\
\hline Cereals enterprises & + & - & - & - \\
\hline
\end{tabular}

\begin{tabular}{|l|l|}
\hline - decrease & -- large decrease \\
\hline+ increase & $=$ little or no change \\
\hline
\end{tabular}

\section{Evidence at regional level}

FEM models were used due to the characteristics of the dataset (panel data) and in order to account for unobservable effects. FEM models account for unobservable factors that change over the unit of observations (the regions in our case), but not across time. These factors might be related to differences in soil type, potential alternative crops, level of investment, meteorological factors such as humidity, rainfall and temperature, and alternative sources of income (i.e. tourism) that can substitute agricultural land for recreational uses. Econometrically, this means that in the regression lines given by expressions (9) and (10) the constant term $\left(\beta_{0}\right)$ will be different for each region (i.e. it can be written as $\beta_{\mathrm{i} 0}$ ). This implies that even if all other factors (CAP payments, total agricultural land and prices) were equal among the regions, some regions will naturally allocate more land to some crops than other regions. The fixed effects coefficients are displayed in Table 4 below.
Fixed effects coefficients show differences between regions due to unobservable factors. For wheat, regions such as North East and North West show relatively small coefficients in comparison with South West and East Anglia. Coefficients for OSR and barley show that unobservable large differences in the number of hectares allocated to these crops exist for North East and South West regions.

Finally, Table 5 shows the impact of CAP on land allocated to wheat, barley and oilseed rape per region in England accounting for the fixed effects. The impact of the reduction in CAP payments, as a result of the reform, will be more severe in those regions with more pronounced fixed effects. Specifically, with respect to wheat, the West Midlands and North West seem to be the most negatively affected by the reduction in CAP payments associated with the CAP reform. On the contrary, Eastern, South Eastern and North Eastern regions are predicted to keep or slightly increase their

Table 4. Estimated Fixed Effects including and excluding production costs

\begin{tabular}{|l|c|c|c|c|c|c|}
\hline \multirow{2}{*}{\multicolumn{1}{|c|}{ Region }} & \multicolumn{2}{c|}{ Excluding production costs } & \multicolumn{2}{c|}{ Including production costs } \\
\cline { 2 - 7 } & Wheat & Barley & OSR & Wheat & Barley & OSR \\
\hline South East & 63.1 & -49.8 & -26.3 & 67.1 & -77.1 & -59.2 \\
\hline South West & 64.3 & -51.3 & -28.1 & 68.4 & -79.4 & -62.0 \\
\hline East Midlands & 63.6 & -50.0 & -26.1 & 67.7 & -77.3 & -59.1 \\
\hline West Midlands & 61.8 & -49.2 & -26.6 & 65.8 & -76.1 & -59.1 \\
\hline East Anglia & 64.6 & -50.1 & -26.6 & 68.7 & -77.8 & -60.1 \\
\hline North East & 59.2 & -47.6 & -25.6 & 63.2 & -73.7 & -57.0 \\
\hline Yorkshire \& Humberside & 62.8 & -49.3 & -26.4 & 66.8 & -76.4 & -59.2 \\
\hline North West & 59.8 & -49.5 & -28.4 & 63.8 & -76.3 & -60.8 \\
\hline
\end{tabular}


Table 5. Impact of the CAP on land allocated to cereals and oilseed rape by region in England

\begin{tabular}{|l|c|c|c|c|c|c|}
\hline \multicolumn{1}{|c|}{ Regional areas } & $\begin{array}{c}\text { Wheat area } \\
\mathbf{2 0 0 3}(\mathbf{h a})\end{array}$ & $\begin{array}{c}\text { Wheat area } \\
\text { change 2012 }\end{array}$ & $\begin{array}{c}\text { Barley area } \\
\mathbf{2 0 0 3}(\mathbf{h a})\end{array}$ & $\begin{array}{c}\text { Barley area } \\
\text { change 2012 }\end{array}$ & $\begin{array}{c}\text { OSR area } \\
\mathbf{2 0 0 3} \text { (ha) }\end{array}$ & $\begin{array}{c}\text { OSR area } \\
\text { change 2012 }\end{array}$ \\
\hline South East & 238,530 & $=/+$ & 74,098 & $=$ & 74,221 & $=$ \\
\hline South West & 174,068 & $=$ & 111,227 & -- & 40,462 & -- \\
\hline East Midlands & 352,722 & $=$ & 90,599 & $=/-$ & 100,978 & $=$ \\
\hline West Midlands & 150,249 & - & 61,628 & - & 32,975 & - \\
\hline Eastern & 481,126 & + & 164,402 & - & 93,858 & - \\
\hline North East & 66,423 & $=/+$ & 42,273 & $=$ & 22,072 & $=$ \\
\hline $\begin{array}{l}\text { Yorkshire and } \\
\text { Humber }\end{array}$ & 233,039 & $=$ & 119,295 & $=/-$ & 53,556 & $=/+$ \\
\hline North West & 28,385 & -- & 53,556 & -- & 3,864 & $=/+$ \\
\hline
\end{tabular}

\begin{tabular}{|l|l|}
\hline - decrease & - large decrease \\
\hline+ increase & $=$ little or no change \\
\hline
\end{tabular}

wheat acreage in response to the policy change. South Western and North Western regions will suffer a large reduction of land allocated to barley. With regard to oilseed rape production, large reductions are expected in the South Western and Eastern regions.

\section{Conclusions}

The results achieved from our empirical analysis lead us to believe that, as a result of the CAP reform, a net downturn in the cereal area will be observable in England as a whole between 2005 and 2012. Moving from a macro onto a micro analysis of our results, we would more specifically say that within cereal farms, barley and oilseed rape acreage will be more affected by the CAP reform. This is due to the fact that some intensification into wheat production is likely to occur. The same can be said at a regional level, where a greater specialisation in wheat is likely, especially in East Anglia. The overall effect will be larger on economically medium and large farms, compared to small farms. This is because the single payment is likely to be higher for smaller farms.

Lowered profitability in some sectors and movement of land away from traditional crops will stimulate development and consideration of diversification options to either add value to current production or to develop alternative revenue streams from new agricultural or other enterprises. While the current regional markets for crop-derived industrial fibres and oils and specialist pharmaceutical and healthcare materials are currently small, and likely to be well-supplied, there is significant potential for regional expansion in crops for bio-energy production. Development of bio-diesel production plants on Teeside alongside existing facilities for production in the Humber and Castleford area, offer good opportunities for the region to supply raw crop materials, given the right stimulus. Such developments would create parallel markets to the existing food markets, without impacting significantly on individual farms or the regional supply chains. The demand for renewable electricity generation has stimulated markets for arable coppice (willow) in the region to supply co-firing plants at Drax Power Station near Selby in North Yorkshire, though cheap import of wood pellets currently restricts the viability of regional supply. However, support for local combined heat and power units is anticipated to grow, leading to the development of local supply chains which offer better prospects for growers in the region and better opportunities for marginal land. There are obviously a number of alternative non-agricultural opportunities for farmers to diversify their sources of income. Tourism, in this sense, offers possibilities in many regions and could be a significant element.

To conclude, we would like to highlight that the analytical approach followed in this work can be used to look at the impact on other crops and on territorial area dimension. However, in order to have a more complete perspective on the effect of the policy reform on the agricultural sector in England, further research on the views of the farmers, with regard to compliance is 
needed. This will contribute to obtaining more accurate estimates of the CAP reform effects on land allocation. Further research is also needed to investigate the unobserved causes of the differences in land allocated to the crops investigated in this regional study.

\section{References}

Agra Europe (2004) July 23.

BENJAMINE, C.; GOHIN, A. and GUYOMARD, H. (1999) The future of European dairy policy. Canadian Journal of Agricultural Economics, 47, p. 91-101.

BOUAMRA MECHEMACHE, Z. and RÉQUILLART, V. (2000) Analysis of EU dairy policy reform. European Review of Agricultural Economics, 27(4), p. 409-430.

BURREL, A. (2004) The 2003 CAP reform Implications for the EU dairy sector. Outlook on agriculture, 33(1), p. $15-25$.

Centre for Rural Economic Research (2003) CAP reform: Decoupling Arable Payment. A discussion document for DEFRA, University of Cambridge.

COLMAN, D.; ZHUANG, Y. and FRANKS, J. R. (2004) UK milk production following the 2003 reform of the CAP. Centre of Agricultural, Food and Resource Economics, The University of Manchester, p. 1-40.

DEFRA (2004) CAP single payment scheme: basis for allocation of entitlement, DEFRA Report. Available from Internet: $<$ http://www.defra.gov.uk/farm/capreform/implementtion/docs/webnoterev16.pdf>.

DEFRA (2003) Updated Regulatory Impact Assessment on the European Commission's proposals of January 2003 for the Reform of the Common Agricultural Policy, DEFRA Report.

EU Commission (2003) Mid-Term Review of the Common Agricultural Policy. Directorate General for Agriculture. Available from Internet: <http://europa.eu.int/comm/agriculture/public/reports/refomimpact/rep_en.pdf $>$.

EU Commission (2003) Reform of the Common Agricultural Policy. A Long Term Perspective for Sustainable Agriculture. An Impact Analysis, European Commission, DirectorateGeneral for Agriculture. Available from Internet: <http://
europa.eu.int/comm/agriculture/publi/reports/refoRimpact/ rep_en.pdf $>$.

EU Commission (2001) Risk Management Tools for EU Agriculture. Working Document by the General Directorate for Agriculture. Available from Internet: <http://www.europa. eu.int/comm/agriculture/publi/insurance/text_en.pdf $>$.

GRANT, W. (2003) The prospects of CAP reform. The Political Quarterly, 74(1), p. 19-26.

GUYOMARD, H.; BAUDRY, M. and CARPENTIER, A. (1996) Estimating crop supply response in the presence of farm programmes: application to the CAP. European Review of Agricultural Economics, 23, p. 401-420.

HARRIS, D. (2005) Industry adjustment to policy reform. A case study of the Australian dairy industry. Rural Industries Research and Development Corporation, p. 1-87.

MOSS, J.; MCERLAN, S.; KOSTOV, P.; PATTON, M.; WESTHOFF, P. and BINFIELD, J. (2002) Analysis of the impact of modulation on agriculture in UK. Queen's University of Belfast, Ireland. Available from Internet: < http:// www.qub.ac.uk/afe/fapri/UKModulation.pdf $>$.

NERLOVE, M. (1958) The dynamics of supply: Estimation of farmers' response to price. Baltimore: John Hopkins Press.

OFFICIAL JOURNAL OF THE EUROPEAN UNION (2003) Establishing Common Rules for Direct Support Schemes Under the Common Agricultural Policy and Establishing Certain Support Schemes for Farmers and Amending Regulations (EEC) No. 2019/93, (EC) No. 1452/2001, (EC) No. 1453/2001, (EC) 1454/2001, (EC) 1868/94, (EC) No. 1251/1999, (EC) No. 1254/1999, (EC) No. 1673/2000, (EEEC) No. 2358/71 and (EC) No. 2529/2001, Council Regulation (EC) No. 1782/2003, Brusselles.

SKOKAI, P. and ANTÓN, J. (2005) The degree of decoupling of area payments for arable crops in the European Union. American Journal of Agricultural Economics, 87(5), p. $1220-1228$.

SWINBANK, A. and TRANTER, R. (2004) A bond scheme for common agricultural policy reform. CABI.

WOOLDRIDGE, J. M. (2002) Econometric analysis of cross section and panel data. Massachusetts Institute of Technology Press. 